\title{
Wolff-Parkinson-White Syndrome after Fontan-Bjork operation and its Successful Ablation from Coronary Sinus
}

\author{
Mustafa Yolcu \\ Department of Cardiology, Medicine Faculty, Yeni Yuzyil Universty, Istanbul, Turkey
}

\begin{abstract}
Wolff-Parkinson-White (WPW) syndrome causes paroxysmal supraventricular tachycardia in which short PR intervals and delta waves are seen in electrocardiography, which may cause sudden cardiac death. A 19-year female presented with increasing episodes of wide and narrow QRS complex tachycardia for the past 5 years. She had tricuspid atresia and Fontan Bjork operation in her past history. She was then diagnosed with narrow QRS complex tachycardia; and WPW syndrome was discovered when she returned to sinus rhythm. Ablation was performed from the coronary sinus ostium region via the left subclavian vein. Fontan Bjork procedure leading to accessory connections stemming from the surgery in the atrio-infundibular anastomosis may be one reason for WPW syndrome. In this case, since the ablation area was close to the Fontan anastomotic line, it could not be determined clearly whether WPW syndrome was secondary to Fontan anastomosis or it was congenital occult WPW syndrome, which became overt following Fontan surgery.
\end{abstract}

Key Words: Wolff-Parkinson-White Syndrome, Fontan-Bjork operation, Supraventricular tachycardia.

How to cite this article: Yolcu M. Wolff-Parkinson-White Syndrome after Fontan-Bjork operation and its successful ablation from coronary sinus. J Coll Physicians Surg Pak 2019; 29(9):886-7.

\section{INTRODUCTION}

Wolff-Parkinson-White (WPW) syndrome causes paroxysmal supraventricular tachycardia in which short PR intervals and delta waves are seen in electrocardiography (ECG), which may cause sudden cardiac death. ${ }^{1}$ Fontan operation is total cavo-pulmonary anastomosis and usually increases tendency to supraventricular arrhythmia.2,3

Here, we are presenting a WPW syndrome case in a 19-year female, which became apparent after Fontan operation leading to frequent narrow and wide QRS complex tachycardia, which received ablation treatment.

\section{CASE REPORT}

A 19-year female patient presented with wide and narrow QRS complex tachycardia for the last 5 years. She was diagnosed with narrow QRS complex tachycardia; and WPW syndrome was discovered when tachycardia turned into sinus rhythm. She had tricuspid atresia and Fontan operation in her history. The family stated that they were told that there were no problems in the ECGs performed in early years in the perioperative period and that there were no rhythm disorders. Despite all the medical treatments, the patient continued to have frequent tachycardia attacks. Thus, ablation was decided for the patient. In the surface ECG examination,

Correspondence to: Dr. Mustafa Yolcu, Department of Cardiology, Medicine Faculty, Yeni Yuzyil Universty, Istanbul, Turkey

E-mail: yolcudoctor@gmail.com

Received: November 07, 2018; Revised: March 08, 2019;

Accepted: March 21, 2019 it was considered that pre-excitation was in the right postero-osetal or coronary sinus (CS) area. For this, it was firstly proceeded to the small right ventricle through the ventricular septal defect in a retro-aortic way. However, continued activity was observed with the mapping in that region. Then, upper-left venous angiography was performed in terms of a probable persistent left superior vena cava. Here, it was demonstrated that the left superior vena cava opened into both the brachiocephalic vein and the coronary sinus in a dual way (Figures $1 \mathrm{~A}$ and $1 \mathrm{~B}$ ). By placing a $7 \mathrm{~F}$ sheath in the left subclavian vein and entering from there with the Mariner catheter, continuous activity was demonstrated in the CS ostium secundum (OS) region and ablation was performed (Figures 1C and 1D). The sinus rhythm was achieved (Figure 2A). Following this, pre-excitation could not be shown with the atrioventricular programmed electrical stimulation (Figures $2 \mathrm{~B}$ and $2 \mathrm{C}$ ). The patient did not have any tachycardia in 3-year follow-up, and no pre-excitation was detected in the ECG.

\section{DISCUSSION}

When tricuspid atresia is not detected and treated at an early age, it carries a high mortality risk. WPW syndrome is a pre-excitation syndrome that has sudden cardiac death risk.1-4

Following the atrioventocular (AV) Fontan surgery, the incidence of the accessory pathways increases in patients who have tricuspid atresia. ${ }^{5}$ In this scenario, there are 2 pathways for the development of different accessory pathway (AP): a congenital pathway (Classic 
WPW syndrome, occult or manifest); and a surgically created atrio-infundibular pathway. ${ }^{5}$ Following a FontanBjork procedure, accessory connections stemming from surgery in the atrio-infundibular anastomosis pose

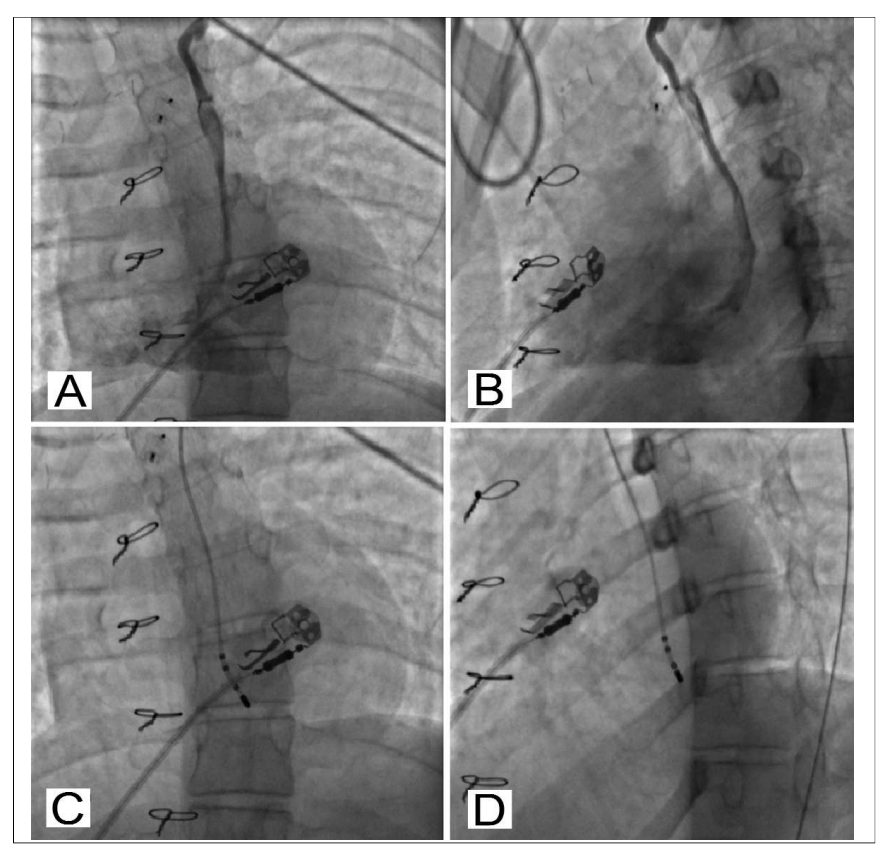

Figure 1: $(\mathbf{A}, \mathbf{B})$ Angiographic views of coronary sinus via subclavian vein. (C,D) Radiofrequency ablation views.

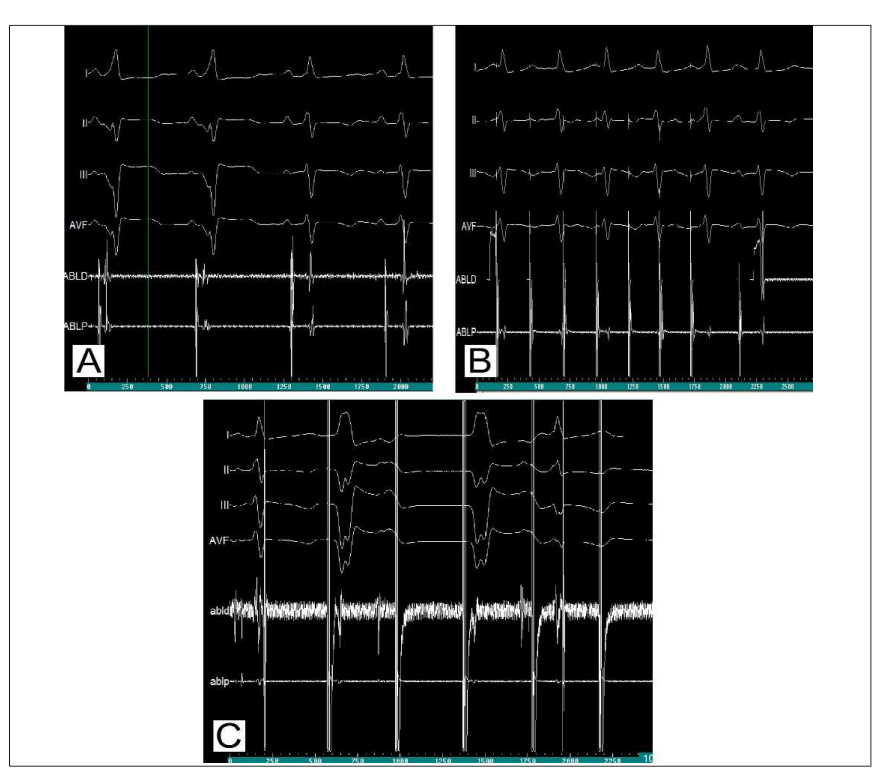

Figure 2: (A) Sinus rhythm and pre-excitation during ablation. (B,C) No preexcitation by electrophysiology stimulation with atrial and ventricular.

another risk for WPW syndrome. ${ }^{5}$ Razzouk et al. described the finding APs via right atrial to right ventricular anastomosis in a patient who had supraventricular tachycardia after Fontan surgery in 1992.6

Hager et al. conducted a study and reported the outcomes of electrophysiology study in 5 patients who had WPW syndrome in association with tricuspid atresia, which was treated with Fontan-Bjork procedure and hemodynamically symptomatic AV reentrant tachycardia. ${ }^{3}$

In this case, Fontan operation was performed previously, and the family stated that there were no rhythm disorders in the perioperative period. The patient had frequent tachycardia and developed both wide and narrow QRS complex tachycardia that was resistant to medical treatment, and ablation was decided for her. However, it was determined that the only route for endocardial ablation catheter to reach the right-side APs was via the left superior vena cava which opened into the left brachiocephalic and the coronary sinus in a dual way and ablation was performed by entering through this route. In this case, since the ablation area was close to the Fontan anastomosis line, it could not be determined clearly whether pre-excitation was secondary to Fontan anastomosis or it was congenital non-apparent WPW syndrome, that became apparent following surgical procedure.

In order to eliminate the congenital APs, all patients must be evaluated preoperatively to exclude congenital APs before a Fontan operation. When APs are detected, they must be mapped and ablated.

\section{CONFLICT OF INTEREST:}

Author declared no conflict of interest.

\section{AUTHOR'S CONTRIBUTION:}

MY: Did the ablation of the patient, collected all the data about the article, followed the writing and sending the article.

\section{REFERENCES}

1. Obeyesekere M, Gula LJ, Skanes AC, Leong-Sit P, Klein GJ. Risk of sudden death in Wolff-Parkinson-White syndrome: How high is the risk? Circulation 2012; 125:659-60.

2. Triedman JK. Arrhythmias in adults with congenital heart disease. Heart 2002; 87:383-9.

3. Hager A, Zrenner B, Brodherr-Heberlein S, SteinbauerRosenthal I, Schreieck J, Hess J. Congenital and surgically acquired Wolf-Parkinson-White syndrome in patients with tricuspid atresia. J Thorac Cardiovasc Surg 2005; 130:48-53.

4. Obeyesekere MN, Leong-Sit P, Massel D, Manlucu J, Modi S, Krahn $A D$, et al. Risk of arrhythmia and sudden death in patients with asymptomatic preexcitation a meta-analysis. Circulation 2012; 125:2308-15.

5. Peinado R, Gnoatto M, Merino JL, Oliver JM. Catheter ablation of multiple, surgically created, atrioventricular connections following Fontan-Bjork procedure. Europace 2007; 9:848-50.

6. Razzouk AJ, Gow R, Finley J, Murphy D, Williams WG. Surgically created Wolff-Parkinson-White syndrome after Fontan operation. Ann Thorac Surg 1992; 54:974-7. 